\title{
ANÁLISE CRÍTICA DOS PROCESSOS ESTRUTURAIS NA PERSPECTIVA DA PROCESSUALIDADE DEMOCRÁTICA
}

\author{
CRITICAL ANALYSIS OF STRUCTURAL PROCESSES FROM \\ THE DEMOCRATIC PROCESSUALITY PERSPECTIVE
}

\author{
ZAPHIA BORONI SOUZA ${ }^{1}$ \\ ADRIANO DA SILVA RIBEIRO ${ }^{2}$ \\ SÉRGIO HENRIQUES ZANDONA FREITAS ${ }^{3}$
}

\section{RESUMO}

0 artigo busca apresentar a conceituação e os aspectos que deram origem ao denominado processo estrutural, com o objetivo de questioná-lo frente às conjecturas da processualidade democrática no Estado

1 Mestranda em Instituições Sociais, Direito e Democracia, na linha de Pesquisa em Esfera Pública, Legitimidade e Controle, da Universidade FUMEC. Bacharel em Direito pela Universidade FUMEC. Especialista em Direito Público pela Universidade Cândido Mendes/Rio de Janeiro e em Direito processual: estudos no Estado Democrático de Direito Constitucional pela Universidade FUMEC. Analista Jurídico do Ministério Público de São Paulo. Lattes iD: http://lattes.cnpq.br/6580480534768424. E-mail: zaphiab@gmail.com.

2 Doutor em Ciências Jurídicas e Sociais pela Universidad del Museo Social Argentino - UMSA (2019). Mestre em Direito da Faculdade de Ciências Humanas da Universidade FUMEC. Editor Assistente e Responsável Técnico na Revista Meritum do PPGD/FUMEC. MBA em Gestão Municipal pela Faculdade Unyleya (2018). Especialista em Direito do Estado pela Universidade Dom Pedro Segundo (2018). Especialista em Direito Administrativo pela Universidade Gama Filho (2013). Bacharel em Direito da PUC Minas (2010). Pesquisador no Instituto Mineiro de Direito Processual (IMDP). Editor Chefe das Revistas e Pesquisas do IMDP. Integrante do Grupo de Pesquisa em Direito Processual (GEPRO) registrado no CNPq. Associado do Conselho Nacional de Pesquisa e Pós-graduação em Direito (CONPEDI). Associado do Instituto Popperiano de Estudos Jurídicos (INPEJ). Membership do CAED-Jus. Articulista e Parecerista de Periódicos Jurídicos Nacionais e Internacionais. Professor Orientador no Grupo Educacional IESLA/ESJUS. Professor da disciplina Teoria Geral do Estado no IEC/PUCMinas, em parceria com EJEF/TJMG (2013). Servidor Público do Tribunal de Justiça do Estado de Minas Gerais, desde 1995. Assessor Judiciário do Superintendente Adjunto da Superintendência Administrativa do Tribunal de Justiça do Estado de Minas Gerais. Lattes iD: http://lattes.cnpq.br/2662848014950489. Orcid iD: https://orcid.org/0000-0002-66583179. Publons: AAM-4092-2020. E-mail: adrianoribeiro@yahoo.com.

3 Pós-Doutor em Democracia e Direitos Humanos pela Faculdade de Direito da Universidade de Coimbra (Portugal). Pós-Doutor em Direito pelo Programa de Pós-Graduação Stricto Sensu em Direito (PPGD) da Universidade do Vale do Rio dos Sinos - UNISINOS (São Leopoldo/RS). Doutor, Mestre e Especialista em Direito pela Pontifícia Universidade Católica de Minas Gerais (PUC MINAS). Professor da Faculdade de Ciências Humanas, Sociais e da Saúde (FCH) da Universidade FUMEC, aonde é docente permanente da Graduação, Especialização e do Programa de Pós-Graduação Stricto Sensu em Direito (PPGD), desde 2009. Magistério na Pontifícia Universidade Católica de Minas Gerais, como Professor convidado desde 2005. Fundador e Coordenador Geral do Instituto Mineiro de Direito Processual (IMDP). Associado e Diretor Departamental do Instituto dos Advogados de Minas Gerais (IAMG). Associado do Conselho Nacional de Pesquisa e Pós-graduação em Direito (CONPEDI) e da Associação Brasileira de Ensino do Direito (ABEDI). Membro honorário da Academia Brasileira de Direito Processual Civil (ABDPC). Bacharel em Direito pela Faculdade de Direito Milton Campos (1998). Associado fundador na perspectiva da processualidade democrática. Revista Meritum, Belo Horizonte, vol. 15, n. 3, p. 124-139, Set./Dez. 2020. DOI: https://doi.org/ 10.46560/meritum.v15i3.8298. 
Democrático de Direito desenvolvidas com base na teoria neoinstitucionalista do processo. 0 texto abordará os aspectos introdutórios da processualidade democrática, buscando sintetizar suas principais ideias. Tendo por referencial teórico a teoria neoinstitucionalista do processo, associada aos princípios constitucionais do processo, pretende-se criticar a abordagem à temática do processo estrutural como fruto do ativismo judicial. A pesquisa apresentada é bibliográfica e se utiliza da metodologia de base hipotético-dedutiva, aos moldes da proposta de Karl Popper.

Palavras-chave: Processo estrutural. Processualidade democrática. Teoria neoinstitucionalista do processo. Democraticidade jurídica.

\section{ABSTRACT}

The article seeks to present the conceptualization and aspects that gave origin to the so-called structural process, with the aim of questioning it in the face of the conjectures of democratic process in the Democratic State of Law developed based on the neoinstitutionalist theory of the process. The text will address the introductory aspects of democratic processuality, seeking to synthesize its main ideas. Theoretically, the neoinstitutionalist theory of the process, associated with the constitutional principles of the process, is intended to criticize the approach to the structural process as a result of judicial activism. The research presented is bibliographical and uses the hypothetical-deductive basis methodology, according to the Karl Popper proposal.

Keywords: Structural process. Democratic procedurality. Neoinstitutionalist theory of the process. Legal democracy.

\section{INTRODUÇÃO}

O presente artigo pretende abordar a temática relativa aos processos estruturais ou estruturantes, também denominados de decisões, medidas, reformas estruturais, analisando-a em contraponto às premissas da processualidade democrática, notadamente na perspectiva da teoria neoinstitucionalista do processo.

Para tanto, realizar-se-á estudo acerca do processo estrutural, quanto à sua conceituação, seus objetivos e base histórica, apontando críticas quanto à sua ligação ao protagonismo judicial e, consequentemente, com a teoria do processo como relação jurídica.

Em seguida, será apresentada síntese sobre as premissas da processualidade democrática, tendo como ponto de partida a alocação da Cidadania, no mesmo plano existencial do Estado, dando relevo à atuação do cidadão como verdadeiro condutor de decisões e construtor do ordenamento jurídico, isso em razão da prerrogativa de autoinclusão do cidadão, o que será detalhado ao longo do trabalho.

do Instituto de Ciências Penais (ICP) e do Instituto Popperiano de Estudos Jurídicos (INPEJ). Associado do Instituto Brasileiro de Direito Constitucional (IBDC). Parecerista ad doc da Agência de Fomento FUNADESP (Fundação Nacional de Desenvolvimento do Ensino Privado). Assessor Judiciário no Tribunal de Justiça do Estado de Minas Gerais (desde 1993). Advogado licenciado, filiado a Ordem dos Advogados do Brasil (Seccional Minas Gerais), desde 1998. Gestor da Biblioteca Desembargador Pedro Henriques de Oliveira Freitas (com mais de 6.000 títulos nacionais e internacionais). Livros jurídicos e Artigos científicos publicados no Brasil, América Latina e Europa (desde 1998), com textos citados em bases bibliográficas e jurisprudenciais diversas. Articulista e Parecerista de Periódicos Jurídicos Nacionais e Internacionais (SEER IBICT / QUALIS CAPES). Participação ativa em Congressos Nacionais e Internacionais. Dupla cidadania (Brasil/Itália). Gestor do Portal do IMDP. WWW.IMDP.COM.BR. Site Pessoal: WWW.ZANDONA.PRO.BR. Lattes iD: http://lattes.cnpq.br/2720114652322968. Orcid iD: https://orcid.org/0000-0002-7198-4567. E-mail: sergiohzf@fumec.br. 
Na mesma esteira, abordar-se-á o princípio do acesso à justiça como sendo a base da participação jurídica do cidadão na construção das decisões judiciais, de modo que só será tida por democrática a decisão construída discursivamente.

Por fim, apresentados os pontos relevantes numa abordagem da democraticidade jurídica, critica-se o processo estrutural concebido como decorrência do ativismo judicial, buscando ressignificá-lo sob o olhar centrado nos princípios fundantes da teoria neoinstitucionalista do processo.

A pesquisa aqui desenvolvida é de cunho bibliográfico e tem por metodologia a base lógico-dedutiva, em que se faz uma comparação entre as teorias colocando-as em teste, a fim de se examinar suas possibilidades diante do problema proposto.

\section{IDENTIFICAÇÃO DOS DENOMINADOS PROCESSOS ESTRUTURAIS}

O processo estrutural, também designado decisão estrutural, decisão estruturante ou reforma estrutural, pode ser compreendido como uma nova forma procedimental de tutela diferenciada de direitos fundamentais, em especial de direitos coletivos (BAHIA; NUNES; COTA, 2019, p. 30).

Na concepção de Fredie Didier, Hermes Zaneti e Rafael Alexandria de Oliveira, a decisão estrutural é aquela em que se busca "implantar uma reforma estrutural (structural reform) em um ente, organização ou instituição, com o objetivo de concretizar um direito fundamental, realizar uma determinada política pública ou resolver litígios complexos" (DIDIER; ZANETI; OLIVEIRA, 2017, p. 48-49).

Nesse viés, "o processo estrutural foi primeiramente delineado nos Estados Unidos, diante da percepção de uma nova categoria de litígios, os litígios estruturais"4 (BAHIA; NUNES; COTA, 2019, p. 31).

Conforme delineado por Alexandre Melo Franco de Moraes Bahia, Leonardo Silva Nunes e Samuel Paiva Cota, os litígios estruturais policêntricos, isto é,

contemplam diferentes pontos de influência que interagem entre si de modos diversos. São, ainda, marcados pela existência de violações estruturais de

4 Tais litígios abarcam o que Edilson Vitorelli denominou de litígios de difusão irradiada. Segundo o autor: "Trata-se daquelas situações em que o litígio decorrente da lesão afeta diretamente os interesses de diversas pessoas ou segmentos sociais, mas essas pessoas não compõem uma comunidade, não têm a mesma perspectiva social e não serão atingidas, na mesma medida, pelo resultado do litígio, o que faz com que suas visões acerca de seu resultado desejável sejam divergentes e, não raramente, antagônicas. Essas situações dão ensejo a conflitos mutáveis, multipolares, opondo o grupo titular do direito não apenas ao réu, mas a si próprio. Exemplifique-se com os conflitos decorrentes da instalação de uma usina hidrelétrica. Se, no início do processo de licenciamento, são discutidos os impactos prospectivos da instalação do empreendimento, em seu aspecto social e ambiental, a fase de obras já muda o cenário da localidade, com a vinda de grandes contingentes de trabalhadores que alteram a dinâmica social. Os problemas passam a ser outros, muitas vezes, imprevistos, e os grupos atingidos já não são os mesmos que eram no primeiro momento, em que se decidiam os contornos do projeto. Na seara ambiental, altera-se o curso ou o fluxo das águas do rio, bloqueando-se estradas e separando comunidades antes vizinhas. Pessoas são deslocadas. No meio ambiente natural, a fauna e a flora sofrem impactos expressivos. Com o fim das obras, toda a dinâmica se altera novamente. Muitos trabalhadores que vieram, se vão. Outros permanecem. As pessoas deslocadas formam novos bairros e povoações, que exigem a implementação de novos serviços públicos. Apenas em razão da realização de uma obra, o meio ambiente natural e a dinâmica social se alteram de tal maneira que a sociedade que existia naquele local adquire feições totalmente distintas da que existia originalmente." (LIMA, 2015, p. 97-98). 
direitos, que se dão como resultado de um conjunto de práticas e dinâmicas institucionais, dentro de uma causalidade complexa e de uma multiplicidade de interesses imbricados, muitas vezes antagônicos. Nesse contexto, acabam por demandar a construção de formas procedimentais peculiares para a efetivação e satisfação de direitos (BAHIA; NUNES; COTA, 2019, p. 33-34).

Ainda, tal como salientado por Fredie Didier, Hermes Zaneti e Rafael Alexandria de Oliveira,

O problema estrutural se define pela existência de um estado de desconformidade estruturada - uma situação de ilicitude contínua e permanente ou uma situação de desconformidade, ainda que não propriamente ilícita, no sentido de ser uma situação que não corresponde ao estado de coisas considerado ideal. Como quer que seja, o problema estrutural se configura a partir de um estado de coisas que necessita de reorganização (ou de reestruturação) (DIDIER; ZANETI; OLIVEIRA, 2020, p. 104).

Nesse cenário, Paulo Henrique dos Santos Lucon entende que a expressão processos estruturais designa:

os processos voltados à tutela de direitos cuja atuação não se atinge por atos isolados ou por medidas estanques, pelo contrário, demandam diálogo e cooperação ao longo de todo o procedimento e a adoção de medidas flexíveis que podem ser alteradas de acordo com a modificação das circunstâncias fáticas (LUCON, 2017, p. 12).

Na perspectiva de Ada Pellegrini Grinover, o processo estrutural pode ser encarado como meio apropriado de judicialização das políticas públicas, tendo em vista os por ela denominados "conflitos de interesse público ou estratégicos", que "surgem na sociedade em função da impossibilidade ou dificuldade de fruição dos direitos fundamentais sociais, de natureza prestacional" (GRINOVER, 2016, p. 48).

O termo processo estrutural, segundo aponta Fredie Didier, Hermes Zaneti e Rafael Alexandria de Oliveira, é utilizado como via procedimental estruturada, pois, "parte-se da premissa de que a ameaça ou a lesão que as organizações burocráticas representam para a efetividade das normas constitucionais não pode ser eliminada sem que tais organizações sejam reconstruídas" (DIDIER; ZANETI; OLIVEIRA, 2017, p. 48-49).

Historicamente, trata-se de uma concepção originada no direito norte-americano, notadamente por meio do precedente Brown v. Board of Education (1954), do qual se originou a expressão "Structural injunctions". Por meio daquela ação de caráter coletivo, o Poder Judiciário foi chamado à intervir contra a política de segregação racial admitida nas escolas fundamentais da cidade de Topeka, Kansas, sendo, portanto, que a Suprema Corte decidiu pela inconstitucionalidade da prática discriminatória, todavia, após tentativas infrutíferas de aplicabilidade da decisão, verificou-se que, para se ter efetividade, aquela decisão deveria ser implementada de forma progressiva, a possibilitar gradualmente a eliminação dos obstáculos oriundos da política até então vigente (ARENHART, 2013; BAHIA; NUNES; COTA, 2019).

Owen Fiss (2004) teria sido o primeiro autor a discorrer sobre o tema nos Estados Unidos, sendo que sua doutrina, em verdade, busca dar evidência ao protagonismo judicial, figurando o juiz como intérprete dos valores constitucionais, na medida em que, segundo a doutrina do autor, em síntese feita por Leonardo Silva Nunes, "o Poder Judiciário também 
teria legitimidade (e o dever) para participar do diálogo travado na arena política, a fim de dar concretude aos valores consagrados pela constituição" (NUNES, 2021, p. 689).

Para o autor norte-americano estadunidense,

o processo judicial de caráter estrutural é aquele no qual um juiz, enfrentando uma burocracia estatal no que tange aos valores de âmbito constitucional, incumbe-se de reestruturar a organização para eliminar a ameaça imposta a tais valores pelos arranjos institucionais existentes (FISS, 2004, p. 26-27).

Ao abordar o tema, Fabrício Bastos elenca a temática como decorrência do ativismo judicial, tendo em consideração que "trata-se de modalidade decisória que se (pre)ocupa mais com a efetividade do comando proferido em seu bojo do que com a resolução da relação jurídica processual". Isso porque, segundo ele, "o órgão jurisdicional, além de indicar a solução da contenda, profere uma decisão que ostenta eficácia prospectiva" (BASTOS, 2018, p. 59).

Nota-se, portanto, que a base teórica até então traçada acerca do denominado processo estrutural está, fatalmente, atrelada à dogmática jurídica, mais, notadamente, à teoria instrumentalista do processo, cuja origem é a teoria bulowiana, em que processo se perfaz como uma relação jurídica subjetiva.

Sob essa perspectiva, o juiz é dotado de um saber inato, é visto como autoridade que possui considerável privilégio cognitivo, sendo que a função interpretativa da norma perde relevo face ao próprio interpretante.

A tônica dada pela doutrina tradicional ao processo estrutural gira em torno do protagonismo judicial, em que se parte da premissa de que o juiz será capaz de impor as medidas necessárias ao desdobramento do problema proposto. Fala-se em decisões escalonadas, em que em um primeiro momento, após a análise do processo (tendo-se como referência a visão dogmática), o juiz proferirá uma decisão, que se limitará a fixar de maneira geral as diretrizes para a proteção do direito tutelado. A partir dessa decisão, outras advirão de acordo com a implementação dada às medidas impostas inicialmente.

Como sintetiza Sérgio Cruz Arenhart,

essas decisões podem (e, muitas vezes, devem) ir além da simples especificação do resultado a ser obtido, esclarecendo os meios para tanto. A sentença judicial, ao fixar a consequência esperada, pode impor um plano de ação, ou mesmo delegar a criação desse plano a outro ente, de forma a atingir, de maneira mais pronta e com o menor sacrifício aos interesses envolvidos, o resultado almejado. É o que Ricardo Lorenzetti chama de microinstitucionalidade. 0 provimento estrutural, de fato, muitas vezes deverá assumir a forma de uma "nova instituição", criada para acompanhar, implementar e pensar sobre a realização do escopo da tutela judicial oferecida (ARENHART, 2013, p. 394).

Verifica-se, portanto, o viés autoritário da forma como tem sido tratada a temática, até mesmo, pode-se assim dizer, retirando de cena os principais interessados pelas medidas a serem tomadas, os cidadãos. Seja diante de um litígio complexo, ou ainda, se tratando da implementação de direitos fundamentais, o foco, tal como colocado, gira em torno da figura central do juiz, sendo ele, como expressão divina, quem "oferecerá" uma tutela judicial 
capaz de abranger por completo, ainda que de forma escalonada e gradual, todas as medidas necessárias.

Por complemento, embora não haja legislação que trate do tema, parte da doutrina tem defendido a compatibilidade e operabilidade da utilização do processo estrutural tendo como base $o$ artigo 139, IV do Código de Processo Civil ${ }^{5}$ (BRASIL, 2015), vez que tal dispositivo abarca uma cláusula geral de efetivação ou de atipicidade de medidas executivas.

Por assim ser, o que se evidencia é que o processo estrutural até então trabalhado pela doutrina ignora ponto que, em verdade, deveria dispor de real destaque: a Cidadania como elemento da democracia.

Em vista disso, critica-se a forma como o processo estrutural vem sendo abordado até então, sob um aspecto dogmático, baseado no ativismo judicial, ignorando a principiologia do Estado Democrático de Direito.

\section{NOÇÓES SOBRE A PROCESSUALIDADE DEMOCRÁTICA}

Antes mesmo de se adentrar à tentativa de correlacionar o ideário do processo estrutural numa perspectiva da processualidade democrática, é preciso explanar, ainda que em síntese, sobre os conceitos básicos inerentes ao Estado Democrático de Direito.

A primeira delimitação que se faz diz respeito à Cidadania, visto que, diferentemente da forma como abordada pela dogmática jurídica, em que a Cidadania se subjuga ao Estado, numa abordagem democrática, a Cidadania deve ser compreendida no mesmo nível hierárquico do Estado.

Para Rosemiro Pereira Leal, a Cidadania se caracteriza como "deliberado vínculo jurídico-político-constitucional que qualifica o indivíduo como condutor de decisões, construtor e reconstrutor do ordenamento jurídico da sociedade política a que se filiou" (LEAL, 2002, p. 150-151).

Com base nesta concepção, Roberta Maia Gresta aponta os fundamentos pelos quais a Cidadania não se subordina ao Estado, dispondo que:

(1) a Cidadania não é um beneplácito estatal, mas um vínculo que conecta a pessoa diretamente ao estatuto jurídico-político inscrito na Constituição;

(2) 0 ordenamento jurídico não é uma doação do Estado, mas objeto de construção e reconstrução permanente por meio de decisões (legislativas, administrativas e judiciais); e (3) o cidadão não é mero destinatário da tutela estatal, pois participa dessas decisões como condutor (GRESTA, 2014, p. 9).

Assim, a Cidadania se encaixa em um mesmo nível institucional, isso porque tanto Estado quanto Cidadania são institutos constitucionalmente traçados, portanto, se enquadram em um mesmo plano existencial, isto é, ambos nascem com a Constituição ${ }^{6}$.

5 Art. 139. O juiz dirigirá o processo conforme as disposições deste Código, incumbindo-lhe: [...]IV - determinar todas as medidas indutivas, coercitivas, mandamentais ou sub-rogatórias necessárias para assegurar o cumprimento de ordem judicial, inclusive nas ações que tenham por objeto prestação pecuniária; [...] (BRASIL, 2015).

6 Em complemento a tais pontos, vale mencionar que para Leal a Constituição faz parte do chamado mundo 3, expressão tal cunhada pelo filósofo Karl Popper ao tratar da sua teoria do conhecimento objetivo, isso porque, segundo Leal, "a 
O cidadão, portanto, não é visto apenas como sujeito tutelado, receptor de direitos, subordinado ao Estado, ao reverso, com a Cidadania ocupando um espaço institucionalmente isonômico surge ao cidadão a prerrogativa de autoinclusão, o que lhe concede a possibilidade de que cada um, por si, promova sua própria inserção na ordem jurídica (GRESTA, 2014, p. 10).

$\mathrm{Na}$ visão democrática, que aqui se defende, o homem deve ser compreendido como 'sujeito natural', isto é, a sua própria natureza biológica lhe faz ser titular de direitos que pertencem a todos os homens indistintamente. Com isso, "os sujeitos naturais são investidos, diretamente pela Constituição, em direitos fundamentais" (GRESTA, 2014, p. 55).

Nesse sentido, portanto, é dado ao homem o direito de participar da construção da ordem jurídica, e atendo-se ao ponto deste trabalho, mais precisamente, da construção das decisões judiciais que lhe digam respeito. A materialização dessa participação, que se coloca como 'elemento jurídico autônomo e nuclear da Cidadania', está exatamente na prerrogativa de 'autoinclusão', defendida por Leal, devendo esta ser encarada como a possibilidade dada ao sujeito de efetivamente discutir o conteúdo dos atos estatais quando de sua produção (GRESTA, 2014, p. 51-52).

Defende-se, então, uma efetiva 'atuação direta', esta compreendida como:

a abertura das instâncias decisórias à participação dos cidadãos, e não apenas à representantes. Em perspectiva jurídica, essa abertura compreende a enunciação de sentidos com caráter vinculativo. Isso significa que não basta que se assegure o comparecimento do cidadão aos locais de deliberação, como ouvinte ou, tampouco, concedendo-lhe oportunidade de manifestação. $O$ ingresso na instância decisória se perfaz quando o sentido enunciado pelo cidadão, ainda que não venha a prevalecer, não pode ser desconsiderado na tomada de decisões (GRESTA, 2014, p. 56).

No âmbito judicial, a atuação direta é analisada sob a perspectiva do acesso à justiça, direito fundamental instituído pela Constituição da República de 1988, que se consubstancia pelo acesso à jurisdição (BRASIL, 1988).

Pondera-se, contudo, que no panorama atual, cuja base é a dogmática jurídica, a interpretação do Direito é dada à autoridade judicial, sendo que o acesso à justiça é abordado no sentido de que ao Judiciário cabe a produção de decisões.

A jurisdição é entendida como a atividade do Estado-juiz que resolve os conflitos que Ihe são postos. Assim, nesse viés, o cidadão se coloca perante o Estado-juiz tão-somente como destinatário de sua decisão, de modo que ao provocar o exercício da jurisdição, imediatamente se sujeita ao juiz, dando causa à formação do processo. Sua participação se reduz a um caráter persuasivo, vez que sua "função" é simplesmente a de influenciar o convencimento da autoridade judicial.

Lado outro, na concepção democrática tratada por Rosemiro Pereira Leal, o acesso à jurisdição é abordado a partir da compatibilidade da atividade decisória estatal (ao que Leal

Constituição surge como uma entidade linguística, autônoma em relação ao contexto histórico em que produzida e às situações concretas que demandam a aplicação do Direito" (GRESTA, 2014, p. 185). Observa-se, nesse sentido, que a teoria do conhecimento desenvolvida por Popper elenca a coexistência de três mundos, sendo que o mundo 1 se perfaz pelos corpos físicos e dos seus estados físicos e fisiológicos, o mundo 2 diz respeito aos estados mentais, enquanto que o mundo 3 é o 
chama de judicação) com as premissas do Estado Democrático de Direito, de modo que "a jurisdição se apresenta como conjunto de conteúdos jurídicos que, produzidos pelo devido processo legislativo, são acessíveis a toda a comunidade jurídico-política" (GRESTA, 2014, p. 58). Assim, alinhando-se a tal percepção, no direito democrático a jurisdição não pode ser identificada como atividade impositiva de uma decisão produzida sob o manto autoritário do Estado-juiz.

Desse modo, em síntese ao pensamento de Leal, esclarece Gresta que a "judicação consiste na estruturação da atividade decisória do Estado sob a forma de procedimentos" (GRESTA, 2014, p. 58), sendo que só se configura de modo democrático quando se apresenta "como dever legal de assegurar às partes o Processo Constitucional e não como atividade tutelar ou interdital de direitos livremente descobertos pela inteligência do julgador à margem do âmbito estrutural do procedimento processualizado" (LEAL, 2014).

Nas democracias, portanto, o juiz ou o decididor "não é livre intérprete da lei, mas o aplicador da lei como intérprete das articulações lógico-jurídicas produzidas pelas partes construtoras da estrutura procedimental". (LEAL, 2014)

Nesse aspecto, "o acesso à jurisdição democrática, portanto, exige a abertura dos procedimentos judiciais aos cidadãos, não apenas formalmente, mas mediante o reconhecimento a estes da qualidade de articulador-construtor da decisão judicial". (GRESTA, 2014, p. 59).

Assim, retomando o princípio constitucional do acesso à justiça, o qual é base à participação jurídica do cidadão na produção da decisão judicial, reitera-se que só pode ser considerada democrática aquela decisão construída discursivamente, isto é, diante da legítima possibilidade que se abre à parte de ser construtora da decisão que lhe afetará.

Indissociável ao direito de petição está a abordagem relativa à legitimidade para estar em juízo. Pondera-se que legitimidade democrática tal como aqui tratado, difere-se de legitimação, habitualmente abordada pela dogmática, pois:

enquanto a legitimidade do exercício das funções estatais é aferida por seu balizamento constitucional, especialmente pela intangibilidade da prerrogativa de autoinclusão da população total, a legitimação envolve um esforço estatal estratégico de estabilização de práticas que vulneram a igualdade institucional entre Estado e Cidadania (GRESTA, 2014, p. 81).

Verifica-se que a legitimidade para estar em juízo é garantia fundamental assegurada constitucionalmente, vez que, nos termos do artigo $5^{\circ}$, XXXV, da Constituição da República, "a lei não excluirá da apreciação do Poder Judiciário lesão ou ameaça a direito" (BRASIL, 1988). De modo que, nessa perspectiva, a lei é ilegítima quando restringe o acesso à jurisdição por meio de uma 'regra de permissão' (ao que dogmaticamente se chama de legitimação), o que se dá, de forma exemplificativa, no âmbito das ações civis públicas (Lei 7.347/85), em que a lei estipula um rol de pessoas ou entes autorizados ${ }^{7}$ a instaurar demandas que suscitem lesão ou ameaça a direitos afetos a coletividade (BRASIL, 1985).

7 Art. $5^{\circ}$, Lei 7.347/85. Têm legitimidade para propor a ação principal e a ação cautelar:

I - o Ministério Público;

II - a Defensoria Pública;

III - a União, os Estados, o Distrito Federal e os Municípios;

IV - a autarquia, empresa pública, fundação ou sociedade de economia mista

V - a associação que, concomitantemente:

a) esteja constituída há pelo menos 1 (um) ano nos termos da lei civil 
A partir desse sentir, ao se compreender democraticamente a legitimidade,

\begin{abstract}
percebe-se que: a) o cidadão somente consegue enunciar sentidos autonomamente em procedimentos estatais quando estes são normatizados como estruturas viabilizadoras da articulação horizontal entre a Cidadania e o Estado; b) a primeira exigência afeta a essa normatização é a não restrição do alcance do princípio da inafastabilidade da jurisdição, pela exclusão, ainda que implícita, de legitimados constitucionais para agir (GRESTA, 2014, p. 85).
\end{abstract}

Significa, então, que como ponto de partida para se viabilizar um processo democrático é necessário não restringir legalmente o acesso do cidadão à jurisdição, preservando-se a prerrogativa constitucional de autoinclusão.

A prerrogativa de autoinclusão tem caráter permanente, constitucionalmente instituída e, portanto, independente da predisposição do Estado para admiti-la. 0 espaço de exercício da Cidadania pressupõe que a criação e a interpretação da lei sejam vinculados ao enfrentamento dos sentidos enunciados pelos cidadãos, como garantia de acesso à jurisdição (GRESTA, 2014, p. 98).

Assim, nesse viés, o interesse em participar da relação processual deve ser autoproclamado, de modo que a "provocação do exercício da função judicial é, por si, a demonstração da existência de interesse de agir, isto é, do interesse em ingressar na instância decisória judicial e enunciar sentidos" (GRESTA, 2014, p. 102).

A construção da processualidade democrática tem por premissa a possibilidade de enunciação livre de interesses, especialmente quando diz respeito ao exercício de direitos fundamentais expressamente trazidos pela Constituição da República.

Sob essas bases defende-se a objetivação dos procedimentos, cujo centro é a argumentação jurídica. Significa, portanto, que o interessado, ao provocar o Judiciário, apresenta sua pretensão, que será confrontada com o ordenamento jurídico a fim de se construir uma decisão judicial.

No procedimento objetivo a análise da pertinência ao debate é redirecionada do sujeito para o objeto (GRESTA, 2014, p. 105), de modo que o foco do processo judicial não será o convencimento do juiz da causa, mas sim a argumentação apresentada para se alcançar a pretensão ali exposta.

A mudança deste panorama tem como alicerce a teoria do conhecimento objetivo de Karl Popper $^{8}$ (1975), que embora tenha se fundado no crescimento da produção científica, possui premissas aplicáveis aos procedimentos decisórios.

A base teórica trazida pelo filósofo austríaco aponta para a importância da função argumentativa, de modo que no âmbito processual, o interessado apresentará os fatos por meio da função descritiva, que tem o condão de expor os fatos conforme sua existência no mundo, porém, é a função argumentativa que permite a formulação de problemas e seu enfrentamento por meio de teorias concorrentes (proposições ofertadas à crítica), com resultados

b) inclua, entre suas finalidades institucionais, a proteção ao patrimônio público e social, ao meio ambiente, ao consumidor, à ordem econômica, à livre concorrência, aos direitos de grupos raciais, étnicos ou religiosos ou ao patrimônio artístico, estético, histórico, turístico e paisagístico.

[...] (BRASIL, 1985).

8 Cuja exposição se deu notadamente na obra "Conhecimento objetivo: uma abordagem evolucionária". Publicada no Brasil pela ed. da Universidade de São Paulo em 1975. 
que exercem uma retrocarga sobre os indivíduos (suas mentes) e a coletividade (tradições) (GRESTA, 2014, p. 106).

De tal modo, nas palavras de Roberta Gresta,

diante de atuação do autoproclamado interessado frente ao órgão judiciário (instauração do procedimento ou intervenção neste), deve-se observar de que modo aquele se manifesta. [...] Se a manifestação alcança as funções superiores da linguagem, por meio da conformação do objeto (função descritiva) e da construção de uma pretensão fundamentada (função argumentativa) a respeito desse objeto, o interessado inaugura ou integra o debate. Desde que formulada, a pretensão se submete a testes no curso do procedimento, pela produção de provas e pelas objeções argumentativas apresentadas por outros partícipes. Ao final, a decisão deve ser resultado da crítica racional, encaminhando a tese que se tenha mostrado mais resistente aos testes de falseabilidade. 0 julgamento corresponde, então, à prevalência de um dos sentidos encaminhados pela argumentação jurídica (GRESTA, 2014, p. 107).

Entretanto, pondera-se que o julgamento não poderá ser definitivo. Isso porque os sentidos enunciados e debatidos ao longo do tramitar processual não serão considerados como dogmas, ou seja, não serão tidos como inquestionáveis ou indiscutíveis, sendo possível sua abertura para rediscussão em outro procedimento, caso for.

Essas concepções vão ao encontro da Teoria Neoinstitucionalista do Processo desenvolvida por Rosemiro Pereira Leal. Desse modo, a partir de agora o trabalho se aterá a breve apresentação desta teoria para, então, em contraponto a ela, fazer crítica ao protagonismo judicial que tem sido o foco nos denominados processos estruturais.

\section{O PROCESSO ESTRUTURAL EM CONTRAPONTO À TEORIA NEOINSTITUCIONALISTA DO PROCESSO}

A teoria neoinstitucionalista do processo, concebida por Rosemiro Pereira Leal (2013), tem como fundamento a teoria popperiana, com destaque ao racionalismo crítico e à formação do conhecimento objetivo tendo por base os critérios de falseabilidade das teorias. Partindo dessas concepções, Rosemiro Pereira Leal desenvolve sua própria teoria estabelecendo críticas acerca da democraticidade jurídica.

A referida teoria tem por escopo inicial romper com a ciência dogmática do direito, ressaltando a autoritariedade dos Estados Liberal e Social, anteriormente vigentes, apontando um novo paradigma de Estado, sendo ele uma instituição acessória e protossignificativa a se configurar [...] como Estado de Direito Democrático já recepcionado na Constituição Brasileira de 1988 com a designação de um Estado Democrático de Direito (art. $1^{\circ}$ ) . (LEAL, 2013, p. 3).

Conforme expõe Rosemiro Pereira Leal,

a teoria neoinstitucionalista tem na Constituição a instituição originária de sua possibilidade existencial; todavia, a própria Constituição, ao se autoproclamar Democrática de Direito, pouco importando o âmbito legiferante de 
sua elaboração, como é a brasileira de 1988, já se põe sob regência da instituição constitucionalizada do processo como condição democratizante e jurídico-discursivo regente da realização, recriação e aplicação dos direitos assegurados no discurso constitucional (LEAL, 2014).

Para essa concepção, tal como esclarece Roberta Maia Gresta, o Estado Democrático de Direito exige a elaboração de uma racionalidade crítica, de forma que:

a) estabeleça sentidos a partir das relações lógicas entre os elementos teóricos colhidos de sua principiologia (conexão entre o mundo 2 e o mundo $3)$; b) produza soluções (provisórias) compatíveis com a matriz instituinte democrática (produção do conhecimento científico no mundo 3); e, daí, c) aplique tais soluções com vistas a refutar a subjetividades e [...] disposições comportamentais, [...] expectativas individuais, coletivas e culturais próprias de modos de vida incompatíveis com a principiologia democrática (GRESTA, 2014, p. 187).

O exercício de interpretar o Direito é realizado de forma isonômica, em que o interpretante se vincula ao sentido normativo dos direitos fundamentais, a possibilitar uma abertura de interpretação e argumentação a todos igualitariamente.

Vale rememorar que no sentido de democracia tal como traçado nessa perspectiva, a Cidadania ocupa o mesmo espaço de existência do Estado, o que viabiliza a autoinclusão do cidadão e uma plena abertura da função judicial à interpretação e à argumentação de conteúdos jurídicos.

A teoria neoinstitucionalista do processo busca redefinir o devido processo legal e para tanto apresenta os princípios do contraditório, ampla defesa e isonomia como balizadores do processo como instituição constitucionalizada, por meio do qual se inaugura permanente abertura crítico-argumentativa. Os princípios em questão são tidos por institutivos, característica que Ihes confere precedência em relação ao exercício da função judicial (GRESTA, 2014, p. 188).

Nas palavras de Leal, o processo, como instituição, se apresenta, portanto, como:

[...] conjunto de princípios e (institutos) jurídicos reunidos ou aproximados pelo texto constitucional com a denominação de devido processo, cuja característica é assegurar, pelos institutos do contraditório, ampla defesa, isonomia, direito ao advogado e livre acesso à jurisdicionalidade, o exercício dos direitos criados e expressos no ordenamento constitucional e infraconstitucional por via de procedimentos estabelecidos em modelos legais (devido processo legal) como instrumentalidade manejável pelos juridicamente legitimados (LEAL, 2014)

Segundo preleciona Leal, a instituição de processo constitucionalizado é o marco jurídico-discursivo de criação dos procedimentos judiciais e também dos legislativos e administrativos, sendo que os seus provimentos (decisões judiciais, leis e decisões administrativas) decorrem do compartilhamento dialógico-processual na comunidade jurídica constitucionalizada, na criação, alteração, reconhecimento e aplicação de direitos (LEAL, 2014).

Assim, tal concepção principiológica cria, por meio do processo, espaço aberto à participação direta de todos os interessados, a permitir, com isso, uma construção conjunta do provimento estatal. 
Verifica-se, por conseguinte, que o processo, para essa proposta, é teoria constitucionalizada e constitucionalizante que viabiliza, pelos princípios do contraditório, da ampla defesa e da isonomia, a instalação de espaços de produção, reprodução e interpretação do direito democrático (LEAL; ARAÚJO, 2016, p. 145).

O princípio do contraditório, como institutivo que é, equivale à dialogicidade necessária entre interlocutores (partes) que se colocam em defesa ou disputa dos direitos alegados, sendo-Ihes ainda possível exercer a liberdade de nada dizerem (LEAL, 2018, p. 155).

Diferentemente da oportunização do dizer e contradizer, e até do não dizer, o contraditório, desenvolvido entre as partes, como princípio constitucional, assegurado no artigo $5^{\circ}$, LV, da Constituição da República de 1988, encontra na teoria neoinstitucionalista uma posição distinta daquela que lhe foi dada por Fazzalari, porque o direito ao contraditório não integra uma simples ritualidade do procedimento para convencer o juiz (LEAL; ARAÚJO, 2016, p. 147). ${ }^{9}$

Na vertente democrática, portanto, o contraditório é base instituinte do processo, referente da democraticidade jurídica, logo, viabilizador da enunciação de sentidos pelos interessados em prol da construção da decisão jurídica, não se limitando a um mero dizer e contradizer para a formação do convencimento do juiz.

Por seu turno, o princípio da isonomia está substancialmente ligado ao procedimento em contraditório, visto que se caracteriza pela igualdade temporal entre o dizer e o contradizer exercido pelas partes processuais na realização construtiva e implementadora do procedimento (LEAL, 2018, p. 155).

A ampla defesa, por sua vez, se correlaciona diretamente aos princípios do contraditório e da isonomia, em razão de que a amplitude da defesa se faz nos limites temporais do procedimento em contraditório (LEAL, 2018, p. 156).

Leal elucida que a defesa deve ser produzida pelos meios e elementos jurídico-sistêmicos por alegações e provas no tempo processual oportunizado pela lei. Significa, portanto, que a defesa há de ser ampla, pressupondo a oportunidade de exaurimento das articulações argumentativas do direito e da produção de provas (LEAL, 2018, p. 156).

Com isso, segundo a abordagem neoinstitucionalista, o processo é instituição regente e atributo de legitimidade de toda criação, transformação, postulação e reconhecimento de direitos pelos provimentos legiferantes, judiciais e administrativos (LEAL, 2018, p. 145).

Ainda nessa seara, Gresta, embasada na teoria neoinstitucionalista, destaca que o processo é demarcado por um espaço de refutação ${ }^{10}$ permanente, que identifica no discurso constitucional binômios que conectam direitos fundamentais e princípios institutivos do processo (GRESTA, 2014, p. 189).

Leal destaca que na teoria neoinstitucionalista,

9 Observa-se que Fazzalari, embora construa seu discurso no sentido de se tentar afastar da teoria do processo como relação jurídica de Bulow, acaba por, assim como Bulow, dando foco ao papel do juiz, de modo que o contraditório perde seu referencial de construtor de decisões cuja legitimidade não se origine do saber pressuposto do julgador. Diferentemente do que ocorre com a teoria neoinstitucionalista do processo, para a qual o contraditório é um referente da democraticidade jurídica (LEAL; ARAÚJO, 2016, p. 147)

10 A expressão 'espaço de refutação' é de autoria de Andréa Alves de Almeida, que em sua obra, Espaço jurídico processual na discursividade metalinguística (Curitiba, CRV: 2012), elenca a "participação democrática como a ocupação do espaço processual, concebido este como um espaço de refutação (testificação por exercício da argumentação) [...]". (GRESTA, 2015, p. 188). 
o processo é uma instituição (linguístico-autocrítico-jurídica), coinstitucionalizante e coinstitucionalizada (constitucional) que se enuncia proposicionalmente pelos institutos (princípios normados) do contraditório-vida, ampla defesa-liberdade, isonomia-dignidade (igualdade). Essa biunivocidade se apresenta como direitos fundamentais fundantes do sistema, líquidos, certos e exigíveis, consoante posto, em caráter pré-cógnito, no bojo do sistema jurídico (LEAL, 2013, p. 40).

Na concepção traçada por Leal, de forma sucinta, o termo contraditório-vida se concebe pela ideia de que o contraditório em si não constitui direito fundamental, mas tão somente se for capaz de realizar o direito à vida humana digna. Já a ampla defesa-liberdade se verifica pela livre manifestação de ideias, sendo coextensivo ao princípio do contraditório, possibilitando a reanálise de uma decisão monocrática por um órgão colegiado. Por fim, a isonomia-dignidade (igualdade) quer dizer que não basta uma igualdade de tempo para manifestação das partes, é necessário que as decisões que Ihes digam respeito sejam compreensíveis, mais ainda, a interpretação do Direito e a possibilidade de requerer a modificação e exclusão de normas deve ser acessível a todos igualitariamente (LEAL, 2013, p. 10-11).

Em suma,

que se busca com a teoria neoinstitucionalista do processo é a fixação constitucional do conceito do que seja juridicamente processo, tendo como base produtiva de seus conteúdos a estrutura de um discurso advindo do exercício permanente da cidadania pela plebiscitarização continuada no espaço processual das temáticas fundamentais à construção efetiva de uma sociedade jurídica de direito democrático (LEAL, 2018, p. 145).

Pelo exposto, nota-se que o cognominado processo/decisão/medida estrutural, embora busque em sua essência a tutela de direitos muito sensíveis, notadamente direitos fundamentais constitucionalmente assegurados, o que se verifica, em verdade, é um discurso autoritário, vez que o centro do que se propõe é o decidir do juiz, caracterizado como decorrência lógica e direta do ativismo judicial.

Conforme já descrito neste trabalho, o processo estrutural se perfaz pela gradual implementação das decisões judiciais, de modo que à medida que a decisão judicial vai sendo colocada em prática é que se terá a exata noção de eventuais problemas surgidos, abrindo-se à verificação de eventuais outras imposições que o caso venha a requerer.

Nas palavras de Sérgio Cruz Arenhart, será a complexidade da causa que, comumente, implicará a necessidade de se tentar várias soluções para o problema apresentado em juízo, de modo que essa técnica de tentativa-erro-acerto é que permitirá a seleção da melhor técnica e a busca por um resultado otimizado (ARENHART, 2013, p. 394).

Critica-se o descompromisso do processo estrutural tal qual vem sendo apresentado pela doutrina, tendo em vista, especialmente, a sua ênfase no protagonismo judicial aliada a não abertura crítico-argumentativa aos interessados.

Entretanto, sem pretender esgotar as possibilidades de discussão acerca do tema, é possível conjecturar tal ideário sob uma perspectiva da processualidade democrática, ressignificando o processo estrutural tendo por base a concepção principiológica trazida pela teoria neoinstitucionalista do processo. 


\section{CONCLUSÃO}

Dessa forma, a realização de uma política pública, a implementação de um direito fundamental, ou mesmo, a resolução de litígios complexos ou de 'difusão irradiada', tanto no âmbito judicial ou administrativo deve ser efetivada por meio de uma procedimentalidade, que tem por alicerce os princípios do contraditório-vida, ampla defesa-liberdade e isonomia-dignidade, em que se cria um espaço aberto à participação democrática de todos os interessados, que assim se autoproclamarem.

O processo, portanto, como viabilizador de uma 'abertura crítico argumentativa', deve possibilitar que os interessados (autoincludentes) efetivamente debatam os conteúdos das decisões estatais quando de sua produção, Ihes sendo possível, assim, a enunciação de sentidos que serão verdadeiramente levados em consideração pelo juízo.

Assim, falar em processos estruturais sob a perspectiva da processualidade democrática significa retirar a ênfase do protagonismo judicial, de modo a oportunizar aos legitimados ampla abertura dialógica na construção de decisões estruturadas. Diga-se decisões em virtude de que, pela complexidade das demandas, as partes chegarão a uma primeira decisão, que não poderá ser definitiva, já que os sentidos ali enunciados e debatidos serão colocados em teste, vez que não poderão ser considerados como dogmas, sendo, então, possível sua rediscussão conforme as necessidades forem surgindo, a proporcionar uma série de decisões em prol do melhor interesse dos legitimados.

\section{REFERÊNCIAS}

ARENHART, Sérgio Cruz. Decisões estruturais no Direito Processual Civil brasileiro. Revista de Processo, vol. 225, Nov./2013

BAHIA, Alexandre Melo Franco de Moraes; NUNES, Leonardo Silva; COTA, Samuel Paiva. Das ações coletivas aos processos estruturais: as formas de tutela diferenciada dos direitos fundamentais. In: Processo coletivo, desenvolvimento sustentável e tutela diferenciada dos direitos fundamentais [recurso eletrônico] / Dierle Nunes; Fabrício Veiga Costa; Magno Federici Gomes (Orgs.) -- Porto Alegre, RS: Editora Fi, 2019. Disponível em: https:// www.academia.edu/39591712/Processo_coletivo_desenvolvimento_sustent\%C3\%A1vel_e_tutela_diferenciada_ dos_direitos_fundamentais_Dierle_Nunes_Fabr\%C3\%ADcio_Veiga_Costa_Magno_Federici_Gomes_Orgs_. Acesso em: 04 nov. 2020.

BASTOS, Fabrício. Grupo de estudos em Tutela Coletiva. Acesso restrito: https://grupodeestudosdetutelacoletiva. club.hotmart.com/lesson/qoODRGIweP/materialdeapoio-rodada-04. 2018. Rodada 04, p. 59.

BRASIL. Constituição da República Federativa do Brasil de 1988. Disponível em: http://www.planalto.gov.br/ccivil_03/Constituicao/Constituicao.htm. Acesso em: 13 out. 2020.

BRASIL. Código de Processo Civil (2015). Lei n. 13.105, de 16 de março de 2015. Institui o Código de Processo Civil. Disponível em http://www.planalto.gov.br/ccivil_03/_ato2015-2018/2015/lei/l13105.htm. Acesso em: 25 set. 2020.

DIDIER JR., Fredie; ZANETI JR., Hermes; OLIVEIRA, Rafael Alexandria de. Notas sobre as decisões estruturantes. Civil Procedure Review, v.8, n. 1: 46-64, jan.-apr., 2017.

DIDIER JR., Fredie; ZANETI JR., Hermes; OLIVEIRA, Rafael Alexandria de. Elementos para uma teoria do processo estrutural aplicada ao 
processo civil brasileiro. Revista do Ministério Público do Estado do Rio de Janeiro, n 75, jan./mar. 2020, p. 101136. Disponível em: http://www.mprj.mp.br/documents/20184/1606558/Fredie_Didier_jr_\%26_Hermes_Zaneti_ Jr_\%26_Rafael_Alexandria_de_Oliveira.pdf. Acesso em: 04 nov. 2020.

FISS, Owen M. Um novo processo civil: estudos norte-americanos sobre jurisdição, Constituição e sociedade. Tradução de: Daniel Porto Godinho da Silva e Melina de Medeiros Rós. São Paulo: RT, 2004.

FREITAS, Sérgio Henriques Zandona, et al . Direito e justiça: Estado Democrático de Direito e Processo Constitucional. Cadernos Jurídicos do IMDP (Instituto Mineiro de Direito Processual), 2010.

FREITAS, Sérgio Henriques Zandona. Devido Processo Constitucional e Institutos Jurídicos de Teoria Geral do Estado Democrático de Direito. Cadernos Jurídicos IMDP nº 11 - $1^{\circ}$ Sem/2015.

FREITAS, Sérgio Henriques Zandona. Os Institutos Jurídicos da Teoria Geral do Estado e o Direito Processual Contemporâneo: Pressupostos para a Efetivação da Jurisdição Constitucional Democrática. In: CALHAO, Antônio Ernani Pedroso; MENEZES, Rafael Lessa Vieira de Sá (Organizadores). Direitos humanos e democracia: estudos em homenagem ao Professor Vital Moreira. Rio de Janeiro, Lumen Juris, 2018.

GRESTA, Roberta Maia. Introdução aos fundamentos da processualidade democrática. Rio de Janeiro: Lumen Juris, 2014.

GRINOVER, Ada Pellegrini. Ensaio sobre a processualidade: fundamentos para uma nova teoria geral do processo. Brasília, DF: Gazeta Jurídica, 2016.

JOBIM, Marco Félix. A structural reform no direito brasileiro e a atuação democrática do Supremo Tribunal Federal na sua implantação. Revista de Processo Comparado, vol. 2/2015, p. 159-179, Jul-Dez/2015.

NUNES, Leonardo Silva. A configuração do procedimento adequado aos litígios estruturais. In: ARENHART, Sérgio Cruz; JOBIM, Marco Félix (Coords.) Processos Estruturais. 3ed, rev., atual. e ampl., Salvador, BA: Editora JusPodivm, 2021.

LEAL, Rosemiro Pereira. Teoria processual da decisão jurídica. São Paulo: Landy, 2002.

LEAL, Rosemiro Pereira. A Teoria neoinstitucionalista do processo: uma trajetória conjectural. Belo Horizonte: Arraes, 2013.

LEAL, Rosemiro Pereira. Teoria geral do processo: primeiros estudos. 12. ed. rev. e atual. - Rio de Janeiro: Forense, 2014. [Minha Biblioteca].

LEAL, André Cordeiro; ARAÚJO, Bruno Amazan Avelar de. Democraticidade jurídica e contraditório nas teorias fazzalariana e neoinstitucionalista do processo. Constituição e democracia Il [Recurso eletrônico on-line] organização CONPEDI/UNICURITIBA; Coordenadores: Anna Candida da Cunha Ferraz, Henrique Ribeiro Cardoso - Florianópolis: CONPEDI, 2016.

LEAL, André Cordeiro; OLIVEIRA, Marcelo Queiroz Alves de. Conjecutras sobre a democraticidade jurídica: o conhecimento nos sentidos subjetivo e objetivo em Karl Popper e seus impactos na teoria neoinstitucionalista do processo. Esfera pública, legitimidade e controle [Recurso eletrônico on-line] organização CONPEDI/UFMG/ FUMEC/Dom Helder Câmara; coordenadores: Marcos Leite Garcia, Heron José de Santana Gordilho, Carlos Victor Muzzi Filho - Florianópolis: CONPEDI, 2015, p. 301-321.

LIMA, Edilson Vitorelli Diniz. Tipologia dos litígios transindividuais: um novo ponto de partida para a tutela coletiva. In: ZANETI JR., Hermes Salvador (Coord.).

Repercussões do novo CPC - Processo coletivo. Salvador: JusPodivm, 2016.

LUCON, Paulo Henrique dos Santos. Fundamentos do processo estrutural. In: JAYME, Fernando Gonzaga; MAIA, Renata Christiana Vieira; REZENDE, Ester Camila G. Norato; LANNA, Helena (Org.). Inovações e modificações do Código de Processo Civil - Avanços, desafios e perspectivas. Belo Horizonte, Del Rey, 2017, p. 11-20.

NUNES, Dierle; STRECK, Lênio Luiz. Como interpretar o artigo 139, IV, do CPC? Carta branca para o arbítrio?. Disponível em: https://www.conjur.com.br/2016-ago-25/senso-incomum-interpretar-art-139-iv-cpc-carta-branca-arbitrio. Acessado em 06 fev. 2019. 
OLIVEIRA, Marcelo Queiroz Alves de. A Jurisprudencialização do Direito Brasileiro e a Teoria Neoinstitucionalista do Processo. Dissertação. (Mestrado em Direito Público). Programa de Pós-graduação em Direito. Universidade FUMEC. Belo Horizonte. 2016. Disponível em http://www.fumec.br/revistas/pdmd/article/view/5635. Acesso em 02 fev. 2019.

Recebido/Received: 08.11.2020.

Aprovado/Approved: 02.12.2020. 